\title{
Effectiveness Of Awareness Program On Disaster Management Among Youth Club Members, Pillaiyarkuppam, Puducherry
}

\author{
*R.Elavarasi
}

\begin{abstract}
:
Disasters are sudden catastrophic events that disrupt patterns of life and property in addition to multiple injuries. India is one of the most disaster prone countries in the world, affecting over all 85\% of Indian land and more than 50 million people thus far. This study was aimed to assess the effectiveness of awareness program on disaster management among the members of the youth club in PillaiyarkuppamPuducherry, 40 samples were selected by using purposive sampling technique and Quasi-experimental design (One group Pre-test- Post-test design) was adopted for the study. The study result shows that the pre-test mean score was 11.85 with the standard deviation 3.12 and in the post-test mean score was increased about 32.5 with standard deviation of 5.03 and p-value $<0.001^{* *}$. The pre- test and post-test mean difference for knowledge was 11.85, 32.5 respectively. Thus there is a significant difference between pre-test and post- test score knowledge on Disaster management. Hence there is a significant improvement in post-test level of knowledge, hence it is highly effective.
\end{abstract}

Keywords: Assess, knowledge, Disaster management, youth club members.

\section{INTRODUCTION}

Disasters are sudden catastrophic events that disrupt patterns of life and property in addition to multiple injuries.1

The organization and management of the resources and responsibilities for dealing with all humanitarian aspects of emergencies among in particular preparedness, response and recovery in order to lessen the impact of disasters. The disaster event that occurs without any prediction. The term disaster is loosely used to refer as any incident, manmade or natural occurrence. ${ }^{1}$
A disaster is a serious disruption, occurring over a relatively short time, the functioning of a community or a society involving widespread human, material, economic or environmental loss and impacts, which exceeds the ability of the affected community or society to cope using its own resources ${ }^{1 .}$

\section{Objectives}

- To assess the knowledge about disaster management.

- To assess the effectiveness of the awareness program on disaster management. 


\section{Need for the study}

In 2017, there were 330 natural disaster events. Asia experienced the highest number of natural disasters, most likely due to its size and susceptibility. ${ }^{8}$

Developing countries suffer the greatest costs when a disaster hits-more than 95\% of all death caused by hazards occur in developing countries, and loss due to natural hazards are 20 time greater (as a percentage of GDP) in developing countries than in industrialized countries. ${ }^{9}$

Disaster can outbreak at any time. At state and individual level disaster preparedness is essential to avoid distress. Disaster causes shock, anxiety and distress among people and lead to frustration. Hence we felt there is a need to assess the knowledge among the rural adolescents who are in the risk of disaster prone areas and planned to develop awareness program for that kind of youth club members in Pillaiyarkuppam.

\section{Methodology}

Quantitative research approach and Quasi-experimental research design was adopted. Purposive sampling technique was used to select the samples (includes both boys and girls of Youth Club in Pillaiyarkuppam) based on the inclusion criteria. The data were collected through interview method and pre-test data collection was done by using Structured questionnaire consists of demographic variables and 40 questions on phases of Disaster Management. Disaster Management Training was given to youth club members and the post-test was conducted after the training. The data were analyzed in terms of both descriptive and inferential statistics

\section{Results}

\section{Major study findings}

Among the youth members selected in the study, majority of them 21 (53\%) were in the age group of 18-24 years and $17(42 \%)$ were in the age group of 25-29 years and $(25 \%)$ in the the age group of $30-39$ years. In gender most of the samples 23(58\%) were males and 17 (42\%) were females. With respect to religion $25(63 \%)$ of them were Hindus and $11(27 \%)$ of them were Christians and $4(10 \%)$ of them were Muslims. Out of 40 samples $13(32 \%)$ were married and $27(68 \%)$ were unmarried. In type of house $14(35 \%)$ were living in pucca house and 26(65\%) were living in kutcha house. In educational status $9(22 \%)$ studied up to secondary school education and $17(43 \%)$ studied up to high school education and 14(35\%) were graduates. In occupational status 15 (37\%) were unemployed and $1(3 \%)$ were selfemployed and 22 (55\%) were daily wage employees and $2(5 \%)$ were other type of employees. In nature of occupation 3(8\%) were sedentary workers and 35(87\%) were moderate workers and 2(5\%) were heavy workers. In most of the samples 21(53\%) had an income of 7001-10,000 and 10(25\%) income was 5001-7000 and 7(17\%) income was $<5000$ and $2(5 \%)$ were $>10,000$. Out of 40 samples $24(60 \%)$ were residing at rural areas and $10(25 \%)$ were in semi urban areas and $6(15 \%)$ were in urban areas. In source of information $32(80 \%)$ got information through social media and $3(8 \%)$ got information through newspaper and 2(5\%) received information through friends. In history of previous exposure $28(70 \%)$ were exposed previously and $12(30 \%)$ were not exposed previously.

The pre-test and post-test level of knowledge regarding disaster management among the members of youth club. In pretest out of 40 samples, no one had adequate knowledge, 1(3\%) had moderate knowledge, 39 (97\%) had inadequate knowledge.

After awareness program 33(82\%) had adequate knowledge, 6 (15\%) had moderate knowledge and 1(3) had inadequate knowledge. In post-test majority of the sample had adequate knowledge. It shows 
that awareness programme on disaster management among the members of youth club was effective.

The pre-test ad post-test knowledge regarding disaster management among the members of youth club. Mean score knowledge level of the disaster management in pre-test was 11.85 with the standard deviation of 3.12 respectively. After implementation of awareness programme, the post-test knowledge mean score was increased about 32.55 with the standard deviation of 5.03 respectively. The improvement of knowledge was statistically tested by Wilcox on signed ranks test which was found to be highly statistically significant at $\mathrm{p}<0.001^{* *}$ level. It indicates that awareness program on disaster management among the members of youth club was effective.

Table 1: Frequency and Percentage Distribution of knowledge on disaster management among youth club members. $\quad N=40$

\begin{tabular}{|c|c|c|c|c|}
\hline \multirow{2}{*}{ Level of Knowledge } & \multicolumn{2}{|c|}{ Pre test } & \multicolumn{2}{c|}{ Post test } \\
\cline { 2 - 5 } & $\begin{array}{c}\text { Frequency } \\
(\text { n) }\end{array}$ & $\begin{array}{c}\text { Percentage } \\
(\%)\end{array}$ & $\begin{array}{c}\text { Frequency } \\
(\text { n) }\end{array}$ & $\begin{array}{c}\text { Percentage } \\
(\%)\end{array}$ \\
\hline Adequate knowledge & - & - & 33 & 82 \\
\hline Moderately knowledge & 1 & 3 & 6 & 15 \\
\hline Inadequate knowledge & 39 & 97 & 1 & 3 \\
\hline Total & 40 & 100 & 40 & 100 \\
\hline
\end{tabular}

Table 1: Shows the distribution of pre-test and post-test level of knowledge regarding disaster management among the members of youth club. In pre-test out of 40 samples, no one had adequate knowledge, $1(3 \%)$ had moderate knowledge, 39 (97\%) had inadequate knowledge.

After awareness program 33(82\%) had adequate knowledge, $6(15 \%)$ had moderate knowledge and 1(3) had inadequate knowledge. In post-test majority of the sample had adequate knowledge. It shows that awareness programme on disaster management among the members of youth club was effective. Hence stated hypothesis (HI) was accepted.

TABLE 2: Comparison of mean and standard deviation of pre-test and post-test knowledge regarding disaster management among youth club members.

\begin{tabular}{|c|c|c|c|c|}
\hline Test & Mean & $\begin{array}{c}\text { Standard } \\
\text { deviation }\end{array}$ & $\begin{array}{c}\text { Wilcox on Signed } \\
\text { Ranks Test }\end{array}$ & p-value \\
\hline Pre test & 11.85 & 3.12 & \multirow{2}{*}{-5.503} & $<0.001^{* *}$ \\
\hline Post test & 32.55 & 5.03 & & \\
\hline
\end{tabular}

${ }^{* *}$ Highly significant at $p<0.001$ level 
Table 2: Depicts that the effectiveness of awareness program on knowledge regarding disaster management among the members of youth club. Mean score knowledge level of the disaster management in pre-test was 11.85 with the standard deviation of 3.12 and the post-test knowledge mean score was increased about 32.55 with the standard deviation of 5.03 respectively. The improvement of knowledge was statistically tested by Wilcoxon sign rank test which was found to be highly significant at $\mathrm{p}<0.001^{* *}$ level. It indicates that awareness program on disaster management among the members of youth club was effective. Hence the stated hypothesis (HI) was accepted.

\section{Conclusion}

The study finding reveals that 33(88\%)subjects had adequate knowledge, $6(15 \%)$ subjects had moderate knowledge, and $1(3 \%)$ had inadequate knowledge during post-test on disaster management among YouthClub members.

\section{Reference:}

1. Park K. Park's textbook of preventive and social medicine, 21st edition ed. Jabalpur: BanarasidasBhanot publishers; 2011. p.736740

2. Lewis, etal. Medical-surgical nursing: Assessment and Management of Clinical Problems., 6th edition. New Delhi: Mosby; 2006. P.117-120

3. Central Bureau of Statistics, Environmental Statistics Book (2015).

4. Polit. Essentials of Nursing Research; Appraising Evidence for Nursing Practice. $7^{\text {th }}$ ed. Philadelphia: Lippincott Company; 2006.p.71-77

5. Thuladhar (2015), Geo environmental disaster 2:5 DOI 10-1186/40677-014-0011-4

6. Menon $\mathrm{K}$, venkatachlam $\mathrm{A}$, Thakur. An introduction to disaster management for class. New Delhi:CBS; 2003.p.83-85

7. Kanga Bam RD., Panda PC, Kanga Bam. Disaster preparedness among the resident community-a case study of Rajiv Gandhi University. International journal of environmental science 2012; 2(3):63-64.

8. Ruth F Craven, Constance J Hirnle. Fundamentals of nursing, 4th edition. Lippincott Williams \& Wilkins, 673.

9. https:// www. statista.com.statistics

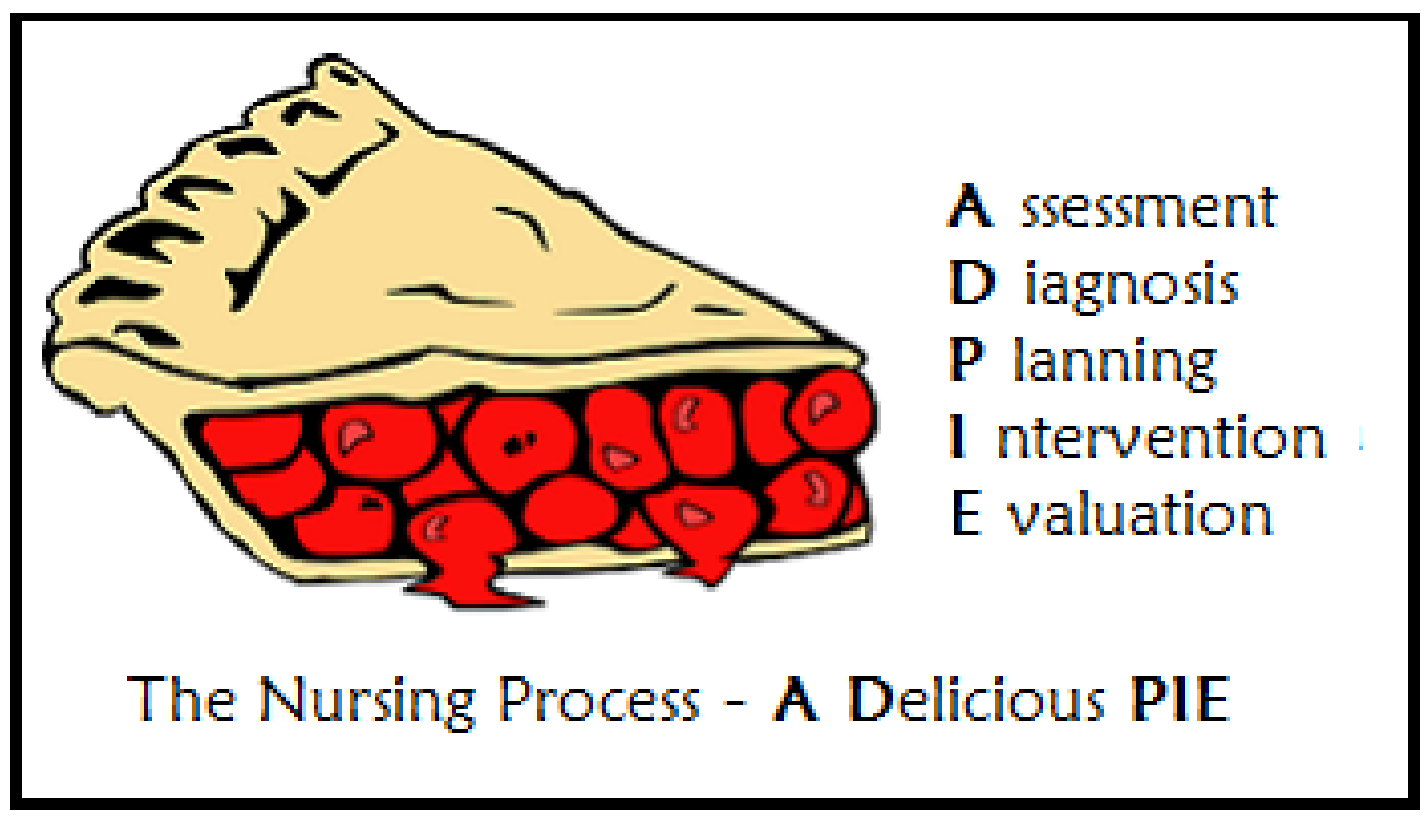

